\title{
Sexual Identity and Substance Use Among Undergraduate Students
}

\author{
Sean Esteban McCabe, PhD, MSW, ${ }^{1,4}$ Carol Boyd, PhD, RN, FAAN,$^{2}$ \\ Tonda L. Hughes, PhD, RN, FAAN, ${ }^{3}$ and Hannah d'Arcy MS ${ }^{1}$
}

This study examined the association between sexual identity and use of alcohol and other drugs (AOD) among college undergraduate students. A survey regarding AOD use was administered to a random sample of 3607 undergraduate students. The sample included 65 self-identified lesbian or bisexual (LB) women and 54 self-identified gay or bisexual $(G B)$ men. Multivariate logistic regression indicated that while alcohol use did not differ for $L B$ and heterosexual women, $L B$ women were significantly more likely to experience certain AOD-related consequences, smoke cigarettes, and use marijuana, ecstasy, and other drugs. $G B$ men were significantly less likely than heterosexual men to drink heavily but were more likely to use some drugs. These findings provide evidence that sexual identity is an important predictor of AOD use among undergraduate students. These findings support the need for continued research and intervention efforts that target LGB collegians.

KEY WORDS: sexual identity; substance use; AOD; consequences; college.

\section{INTRODUCTION}

The majority of alcohol and other drug (AOD) research suggests that lesbian, gay, and bisexual (LGB) adolescents and young adults in the United States are substantially more likely to smoke cigarettes, report alcohol disorders, and use other drugs than are heterosexual youth (1-4). However, several researchers have noted the limitations of research on LGB populations and called for improved research designs and sampling methods $(5,6)$. These researchers encouraged large-scale surveys, using random sampling methods, because LGB health research has relied too often on convenience sampling methods. Although research using convenience samples

\footnotetext{
${ }^{1}$ Substance Abuse Research Center, University of Michigan, Ann Arbor, Michigan.

${ }^{2}$ Substance Abuse Research Center, School of Nursing, University of Michigan, Ann Arbor, Michigan.

${ }^{3}$ College of Nursing, University of Illinois at Chicago, Chicago, Illinois.

${ }^{4}$ To whom correspondence should be addressed at Substance Abuse Research Center, University of Michigan, Ann Arbor, Michigan 48108-1649; e-mail: plius@umich.edu.
} 
has raised awareness about the potential and unique health concerns within LGB populations, the generalizability of results from these studies is limited.

Although studies of LGB populations that have used random sampling methods have generally found higher rates of AOD use than have studies using convenience samples, there are notable exceptions $(2,4,7,8)$. Results of these studies raise questions about the relative risk of substance abuse among LGB groups compared with their heterosexual counterparts. One of the difficulties in comparing results across studies has to do with the lack of consistent definitions of sexual orientation $(1,2,4$, 7,8). For instance, Bloomfield (7) used a random sample of urban adult women in the San Francisco Bay area and found no significant differences in the levels of alcohol consumption between women who identified as lesbian or bisexual and those who identified as heterosexual. In contrast, using sexual behavior as a proxy for lesbian or gay identity, Cochran et al. (2) found that homosexually active women (at least one female sex partner in the year before the survey) in the 1996 National Household Survey on Drug Abuse were at greater risk for alcohol abuse and alcohol-related morbidity than were exclusively heterosexually active women. Alcohol abuse did not differ between homosexually and exclusively heterosexually active men in the study. Gruskin et al. (1) found that women aged 20-34 who self-identified as lesbian or bisexual were more likely than heterosexual women to be drinkers and to report higher weekly alcohol consumption. In a random sample of 4159 high school students, Garofalo et al. (4) found that sexual identity was significantly associated with several risk behaviors including drug use, attempted suicide, and unsafe sexual practices. Finally, Russell et al. (8) compared substance use among 13- to 18-year-old adolescents in a nationally representative sample on the basis of romantic attraction. Adolescent females with romantic attractions to other females or to both females and males were more likely than adolescent females with only other-sex attractions to report higher rates of alcohol intoxication, marijuana use, and other illicit drug use. In contrast, adolescent males who reported attraction to both sexes had significantly higher rates of substance use than did adolescent males with other-sex attractions but there were no differences between adolescent males with same-sex attractions and those with other-sex attractions.

Lack of consistent research results supports the need for further investigations regarding the relationship between AOD use and sexual identity-especially probability studies that examine gender differences in AOD use.

The study of sexual orientation and AOD use among college students has been limited by the fact that these studies have generally lacked questions about sexual orientation (9-11). As in the general literature on AOD use among LGB populations, existing data provide some support for the relationship between sexual orientation or homosexual activity and AOD use among college students $(3,12,13)$. For example, DeBord et al. (12) surveyed a random sample of college students over 4 years and found heavier alcohol use among self-identified LGB college students than among a matched control group of heterosexual college peers. However, there were no differences observed in other drug involvement, suicidal ideation, or measures of psychological distress. In contrast, Pope et al. (13) found that undergraduate students who reported at least one same-sex sexual experience since coming to college reported higher rates of drug use. Boyd et al. (3) found a significant relationship 
between ecstasy use and LGB status after adjusting for several other factors; in fact, self-identified LGB students were three times more likely to report monthly and annual ecstasy use than were heterosexual students. Unfortunately, other measures of AOD use were not examined. The authors concluded that more research on the relationship between sexual orientation and AOD use was needed.

There are several compelling reasons for colleges and universities to learn more about the subgroups of undergraduate students who are at increased risk for AOD misuse. First, AOD misuse among traditional-age undergraduate students is associated with significantly higher rates of unsafe sex $(14,15)$, more emergency care visits $(16,17)$, and higher incidence of sexual assault (18-20). Second, not only is AOD use associated with adverse consequences for students who engage in such behavior, AOD use also has secondary adverse consequences for other students including sleep disturbances, vandalism, and physical attacks $(10,21,22)$. Finally, although noncollegiate LGB populations have been found to be at greater risk for adverse consequences $(8,23-26)$, there is growing consensus that more research is needed that examines the relationship between sexual orientation and consequences of AOD use among college students $(27,28)$.

To better understand the relationship between sexual identity and substance use among undergraduate students, we examined the following hypotheses: (a) selfidentified LB women have significantly higher rates of AOD use and AOD-related consequences than do heterosexual women after controlling for other demographic factors and (b) self-identified GB men have significantly higher rates of AOD use and AOD-related consequences than do heterosexual men after controlling for other demographic factors.

\section{METHODS}

The University of Michigan's Institutional Review Board approved the protocol for this study. The study was conducted during a 1-month period in March and April of 2001 at the University of Michigan, drawing on a total undergraduate population of 21,055 full-time students (10,732 women and 10,323 men). The University Registrar Office randomly selected 7000 full-time undergraduate students from the population. The 7000 randomly selected undergraduate students were randomly assigned to either the web mode $(n=3500)$ or U.S. mail mode $(n=3500)$. Informed consent was obtained from each student participant.

Several strategies were used to maximize response to the study and to encourage valid responses to survey questions. All participants were informed that a research firm, unaffiliated with the University, was contracted to set up the web survey as well as store and maintain data from both modes of data collection. University officials, faculty, and staff were unable to access any contact information connected with the data of any respondent. The web survey was maintained on a hosted secure Internet site running under the secure sockets layer (SSL) protocol to insure respondent data were safely transmitted between the respondent's browser and the server. Finally, all potential respondents were sent letters explaining that participation was voluntary, describing the relevance of the study, and assuring that all responses would be kept confidential. 
The response rate was $63 \%$ for the web mode and $40 \%$ for the U.S. mail mode, and the overall response rate for the study was $52 \%$. Despite the mode differences in response rate, there were no substantive differences in substance use observed between the two modes (29). In fact, the rates of AOD use found in this study were the same as those obtained by major national surveys of college students $(9,30,31)$. Also, the percentage of respondents who identified as gay, lesbian, or bisexual did not differ by mode. Finally, a telephone follow-up survey of 727 randomly selected nonresponders in both modes found that reasons for nonresponse were unrelated to the study variables.

\section{Sample}

The final sample included 3607 undergraduate students (demographic characteristics of the sample are summarized in Table I) Given that the response rates were different by mode, the demographic characteristics of the U.S. mail and web respondents were compared. Respondents differed by survey mode on gender $\left(\chi^{2}=16.4\right.$, $\mathrm{df}=1, p<0.001)$, with fewer males responding in the U.S. mail mode. There were no significant differences in the race, class year, living arrangement, or GPA between the two survey modes.

Overall, the final sample was $58 \%$ female, $68 \%$ White, and $32 \%$ had a senior class standing in college. Student characteristics from the overall undergraduate student population $(N=21,055)$ and the final sample $(n=3607)$ were compared. Significant differences were found for gender and race with the final sample entaining more women and white students and fewer African-American students. Living arrangement and GPA were not known for the population, and thus we could not assess whether the sample was representative with respect to these characteristics. Approximately $3.3 \%$ of the sample identified themselves as LGB, which is consistent with other research using self-report of sexual identity among random samples of adolescents and young adults $(1,4,32,33)$. We were encouraged that $3.3 \%$ of both the U.S. mail and web survey subsamples reported being LGB, which suggests that both survey modes were reasonably successful in reaching LGB students. Among LGB students, more women self-identified as bisexual $(n=49)$ than as lesbian $(n=16)$ and more men self-identified as gay $(n=40)$ than as bisexual $(n=14)$. Demographic characteristics of LGB students were comparable to heterosexual students except for living arrangement. LGB students were less likely to live in residence halls or fraternity or sorority houses and more likely to live in apartments or houses. In comparisons of the demographic characteristics of LGB and heterosexual samples by gender, no significant differences were found between gay/bisexual and heterosexual men. However, lesbian/bisexual women were more likely than heterosexual women to live in houses or apartments $\left(\chi^{2}=18.4, \mathrm{df}=3, p<0.001\right)$.

\section{Instrument}

The Student Life Survey (SLS) was developed and pilot-tested in 1993. The SLS draws from items in the Monitoring the Future study (9), CORE study (10), and 


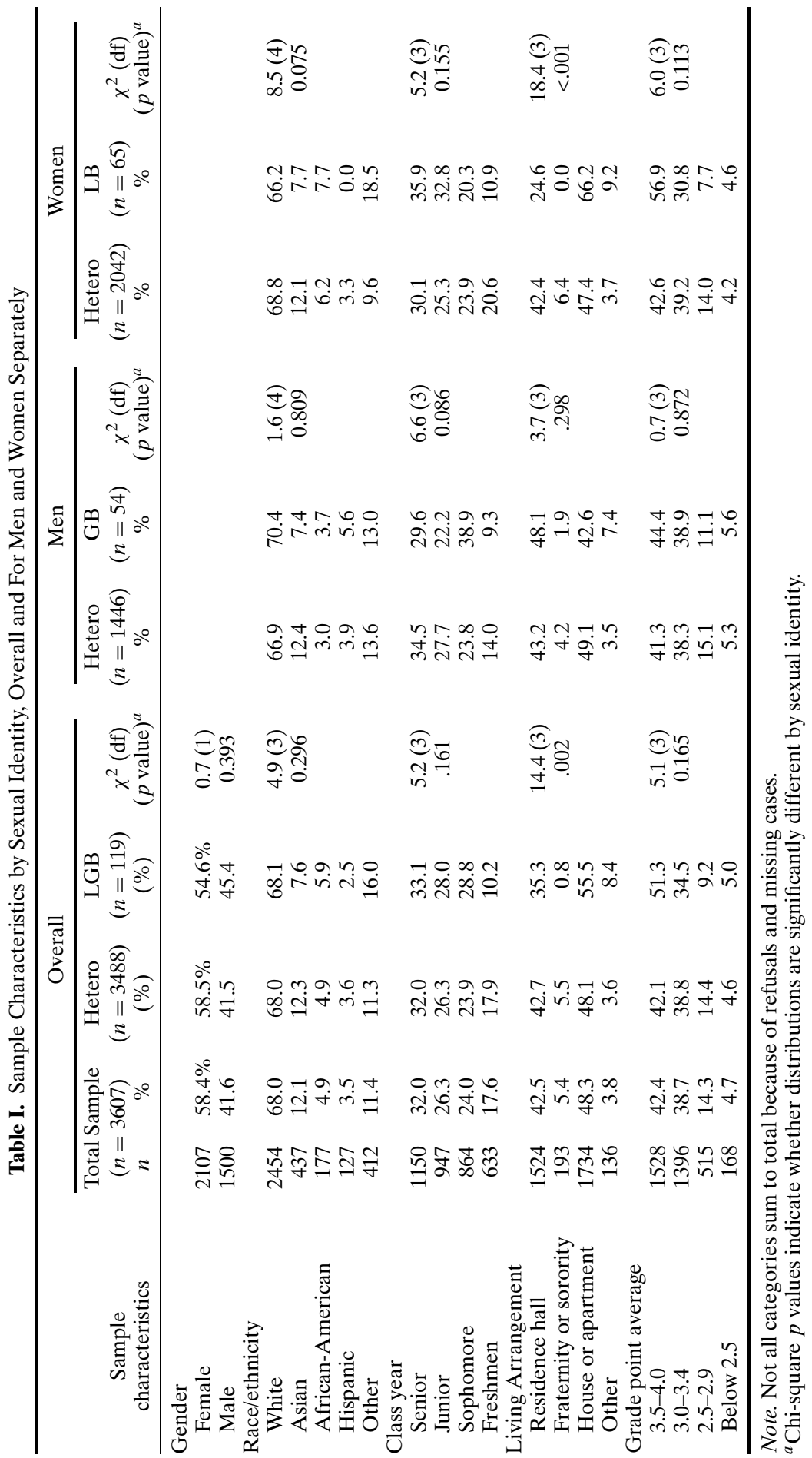


the College Alcohol study (11). Study design, procedures, and reliability measures in SLS are described in more detail elsewhere $(34,35)$.

\section{Measures}

Sexual identity was assessed using a single item that asked whether respondents considered themselves to be (1) heterosexual, (2) lesbian or gay, or (3) bisexual.

Heavy episodic drinking was measured using the following single-item question: "Over the past two weeks, how many occasions have you had five or more drinks in a row (four or more for women)?" A drink was defined as a glass of wine, bottle of beer or wine cooler, a shot of liquor, or a mixed drink. For purposes of this analysis, response categories were collapsed into the following categories: (1) none, (2) 1-2 occasions, (3) 3 or more occasions.

Monthly alcohol use was measured using the following question: "On how many occasions (if any) have you had alcohol to drink - more than just a few sips during the past 30 days?" The response scale was: (1) no occasions, (2) 1-2 occasions, (3) 3-5 occasions, (4) 6-9 occasions, (5) 10-19 occasions, (6) 20-39 occasions, and (7) 40 or more occasions.

Cigarette use was measured using the following question: "How many cigarettes did you smoke during the past 30 days?" The response scale was: (1) none, (2) less than 1 cigarette per day, (3) 1-5 cigarettes per day, (4) about 0.5 pack per day, (5) about 1 pack per day, (6) about 1.5 packs per day, and (7) 2 or more packs per day.

Monthly marijuana use was assessed using the following question: "On how many occasions have you used marijuana in the past 30 days?" Seven response choices were provided: (1) none, (2) 1-2 occasions, (3) 3-5 occasions, (4) 6-9 occasions, (5) 10-19 occasions, (6) 20-39 occasions, and (7) 40 or more occasions.

Annual alcohol use was measured using the following question: "On how many occasions (if any) have you had alcohol to drink - more than just a few sips — during the past 12 months?" The response choices for each question were the following: (1) no occasions, (2) 1-2 occasions, (3) 3-5 occasions, (4) 6-9 occasions, (5) 10-19 occasions, (6) 20-39 occasions, and (7) 40 or more occasions.

Annual marijuana use was measured using the following question: "Have you used marijuana in the past 12 months?" For purposes of this analysis, annual marijuana use was considered a dichotomous outcome (at least once/none).

Annual ecstasy use was measured using the following question: "Have you used ecstasy in the past 12 months?" For purposes of this analysis, annual ecstasy use was considered a dichotomous outcome (at least once/none).

Annual and monthly illicit drug indices were developed by summing the total number of illicit drugs used in the past year and in the past month (other than ecstasy and marijuana). The illicit drugs included in the indices were inhalants, psychedelics, LSD, cocaine, narcotics, crystal methamphetamine, downers (e.g. Halcion, Dalmane, barbiturates), heroin, GHB, rohypnol, amphetamines, and tranquilizers. Given the skewed distribution of the drug indices, responses were collapsed into two categories: no use, one or more illicit drugs.

Primary alcohol-related consequences were assessed using items adapted from two national studies of AOD use among college students $(10,11)$. Participants were 
asked 23 questions about primary consequences associated with their use of alcohol in the past year (e.g., drove under the influence, afraid you were alcoholic, unplanned sex, hangover, memory loss, trouble with police, damaged property).

Secondary consequences were assessed using items adapted from the College Alcohol Study $(21,22)$. These included 10 questions about secondary consequences associated with others' AOD use in the past year (e.g., your sleep was disrupted, you experienced an unwanted sexual advance by someone drunk or high, you had to take care of someone with a drinking or drug problem).

Place of residence was determined by asking students, "Where did you live during the school year?" For purposes of this study, responses were collapsed into the following four categories: (1) residence hall, (2) fraternity/sorority house, (3) house or apartment within the university city, and (4) other category which included cooperative housing and outside the university city.

\section{RESULTS}

\section{Prevalence of Alcohol and Other Drug Use}

We examined the association of sexual identity and several measures of AOD and other drug use separately for men and women, using chi-square tests and multivariate logistic regression. Results of chi-square tests examining the full response categories for alcohol use and cigarette smoking measures revealed that there were no significantly different distributions in any of the six alcohol use behaviors between LB women and heterosexual women (see Table II). However, chi-square results indicated that LB women were considerably more likely to report cigarette smoking. Furthermore, significant differences between GB and heterosexual men were found in four out of six alcohol use measures including alcohol use in the past year, number of drinks per week, heavy episodic drinking in the past 2 weeks, and average number of drinks per occasion. Although $91 \%$ of GB men consumed alcohol in the past year (vs. $83 \%$ of heterosexuals), a smaller percentage reported using alcohol 40 or more times ( $21 \%$ vs. $32 \%$ of heterosexuals). Additionally, fewer GB men (30\%) than heterosexual men $(48 \%)$ reported any heavy episodic drinking in the past 2 weeks. Finally, differences in the average number of drinks consumed weekly and per occasion in the past month suggest that while fewer of the GB men abstained from alcohol, they tended to drink more moderately than did heterosexual male drinkers.

In addition to chi-square comparisons, we used multivariate logistic regression to examine the relationship between sexual identity and AOD use adjusting for race, class year, living arrangement, and grade point average. We tested a separate logistic regression model for each of the variables that had shown a significant bivariate relationship with sexual identity for either sex (see Tables III and IV). Because demographic characteristics differed on the basis of sexual identity, it was important to examine the role of sexual identity after adjustment for these substance use variables. In general, White students were more likely than undergraduate students from other racial and ethnic groups to have used alcohol and other drugs. Additionally, underclass (Freshman and Sophomore) students, those with lower grade point 
Table II. Prevalence of Substance Use by Sexual Identity

\begin{tabular}{|c|c|c|c|c|c|}
\hline Substance use measures & $\begin{array}{c}\text { Hetero men } \\
(n=1446)\end{array}$ & $\begin{array}{l}\text { GB men } \\
(n=54)\end{array}$ & $\begin{array}{l}\text { Hetero women } \\
\quad(n=2042)\end{array}$ & $\begin{array}{l}\text { LB women } \\
\quad(n=65)\end{array}$ & $\begin{array}{l}\chi^{2}(p \text { value } \\
\text { differences })\end{array}$ \\
\hline \multicolumn{6}{|l|}{ Pre-college drinking } \\
\hline None & 32.4 & 28.3 & 32.7 & 21.9 & \\
\hline Less than Monthly & 23.8 & 34.0 & 27.9 & 28.1 & \\
\hline Monthly & 23.7 & 24.5 & 24.4 & 35.9 & \\
\hline Weekly & 20.1 & 13.2 & 15.0 & 14.1 & \\
\hline \multicolumn{6}{|l|}{ Alcohol use in past year } \\
\hline Never & 16.9 & 9.4 & 12.5 & 3.3 & A \\
\hline $1-2$ occasions & 7.5 & 3.8 & 9.9 & 13.1 & \\
\hline 3-5 occasions & 6.2 & 15.1 & 9.1 & 6.6 & \\
\hline 6-9 occasions & 6.0 & 9.4 & 9.0 & 8.2 & \\
\hline 10-19 occasions & 13.0 & 22.6 & 17.4 & 19.7 & \\
\hline 20-39 occasions & 18.1 & 18.9 & 17.9 & 26.2 & \\
\hline 40 or more occasions & 32.3 & 20.8 & 24.2 & 23.0 & \\
\hline \multicolumn{6}{|l|}{ Alcohol use in past month } \\
\hline Never & 26.2 & 15.1 & 24.1 & 18.3 & A \\
\hline $1-2$ occasions & 16.9 & 32.1 & 21.4 & 23.3 & \\
\hline $3-5$ occasions & 18.1 & 20.8 & 21.9 & 28.3 & \\
\hline 6-9 occasions & 19.8 & 20.8 & 16.6 & 20.0 & \\
\hline 10-19 occasions & 15.0 & 7.5 & 13.1 & 10.0 & \\
\hline 20 or more occasions & 4.0 & 3.8 & 2.8 & 0.0 & \\
\hline \multicolumn{6}{|l|}{ Heavy episodic drinking } \\
\hline Never & 51.8 & 69.8 & 49.4 & 48.3 & $\mathrm{~A}, \mathrm{~B}$ \\
\hline $1-2$ occasions & 21.2 & 22.6 & 29.8 & 41.7 & \\
\hline 3 or more occasions & 27.0 & 7.5 & 20.7 & 10.0 & \\
\hline \multicolumn{6}{|l|}{ Drinks per occasion } \\
\hline Did not drink & 28.6 & 14.8 & 25.6 & 21.7 & A \\
\hline $1-3$ drinks & 23.6 & 48.1 & 35.8 & 46.7 & \\
\hline 4-7 drinks & 33.6 & 31.5 & 34.9 & 28.3 & \\
\hline 8 or more drinks & 14.2 & 5.6 & 3.7 & 3.3 & \\
\hline \multicolumn{6}{|l|}{ Weekly drinks } \\
\hline None & 31.1 & 22.2 & 32.0 & 27.7 & A \\
\hline 1-2 drinks & 9.8 & 25.9 & 13.4 & 16.9 & \\
\hline 3-6 drinks & 14.4 & 13.0 & 19.9 & 29.2 & \\
\hline $7-20$ drinks & 24.6 & 18.5 & 18.4 & 9.2 & \\
\hline 21 or more drinks & 20.1 & 20.4 & 16.3 & 16.9 & \\
\hline \multicolumn{6}{|l|}{ Cigarette smoking } \\
\hline None & 77.8 & 68.5 & 77.6 & 51.6 & $\mathrm{~A}, \mathrm{~B}$ \\
\hline$<1$ per day & 9.9 & 5.6 & 12.1 & 20.3 & \\
\hline $1-5$ per day & 6.4 & 9.3 & 6.3 & 14.1 & \\
\hline $1 / 2$ pack or more daily & 5.9 & 16.7 & 4.0 & 14.1 & \\
\hline
\end{tabular}

Note. Sample sizes may vary due to missing responses to substance use questions.

"A" indicates distributions for heterosexual men differed significantly from gay/bisexual men $(p<0.05)$. " $\mathrm{B}$ " indicates distributions for heterosexual women differed significantly from lesbian/bisexual women $(p<0.05)$.

averages, and those living in fraternities or sororities were also more likely to have used marijuana, cigarettes, and alcohol.

After controlling for race, class year, living arrangement, and grade point average, there were no significant differences in the drinking behaviors between LB women and heterosexual women. However, as illustrated in Table III, LB women were approximately four times more likely to have smoked cigarettes in the past month, almost twice as likely to have initiated marijuana use before entering college, more than twice as likely to report marijuana use in the past month, and more 


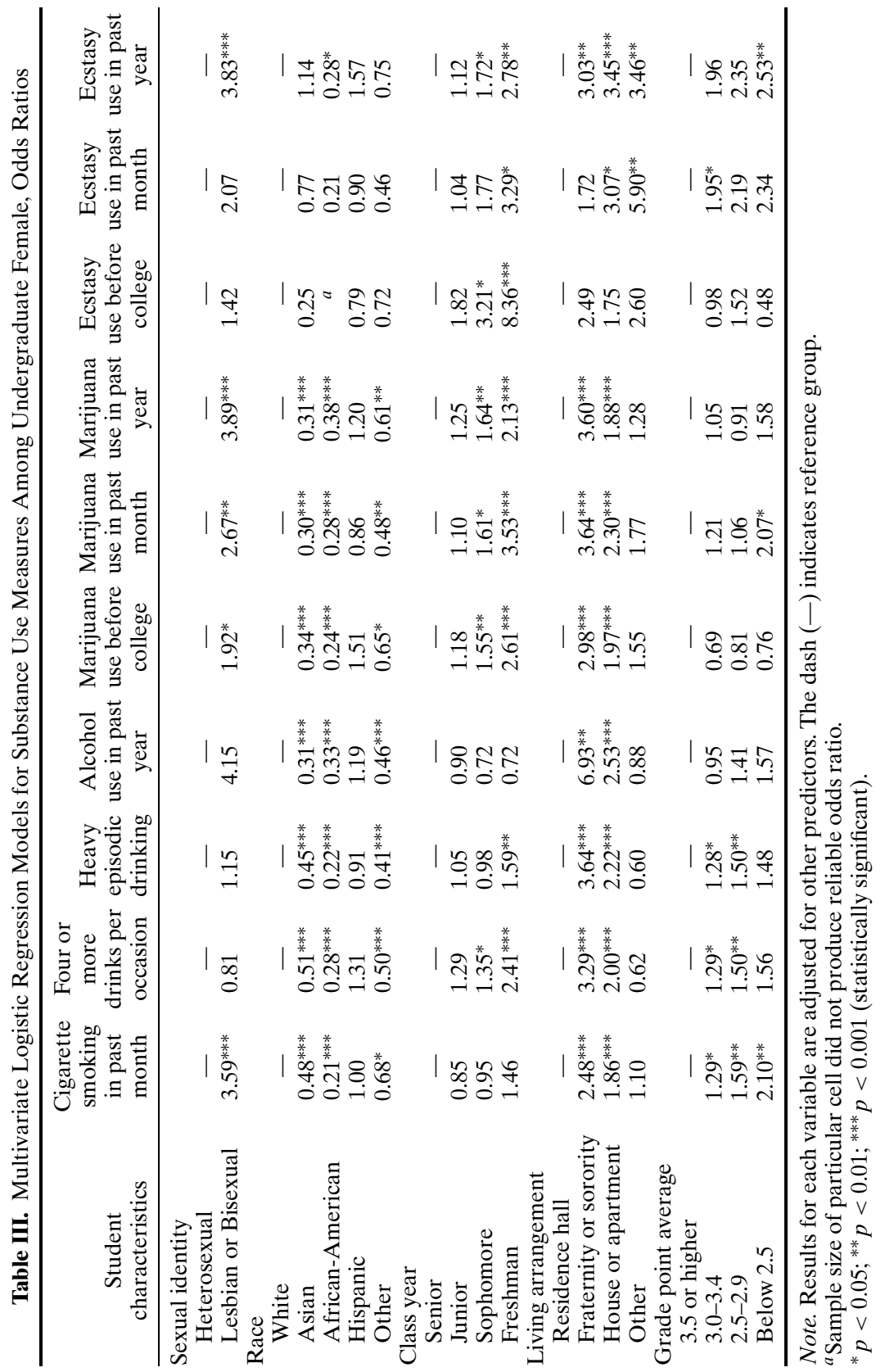




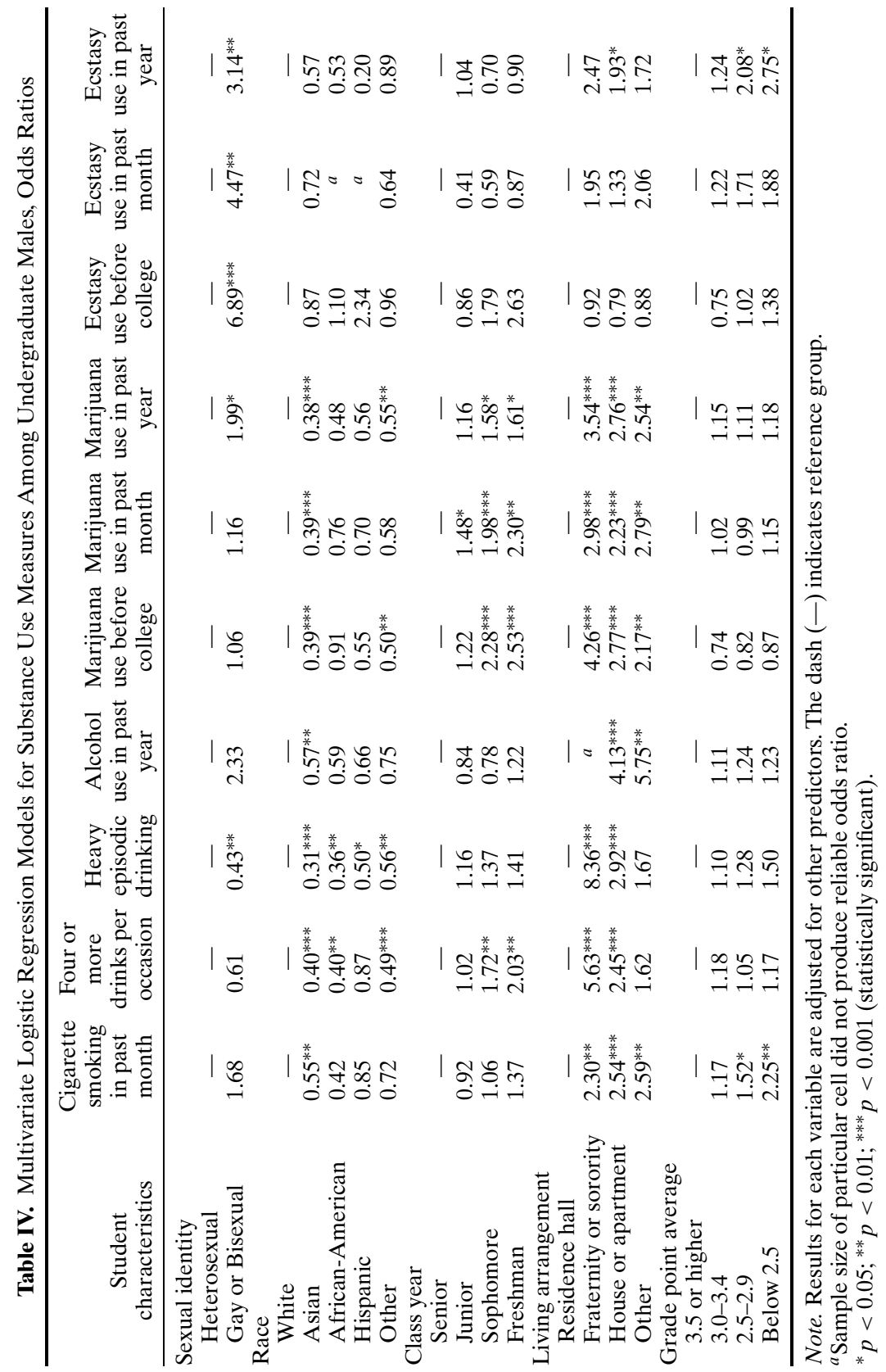


than three times likely to use marijuana and ecstasy in the past year. Additionally, LB women were more than three times as likely to report using at least one illicit drug (other than marijuana and ecstasy) from the monthly illicit drug index (OR = 3.64 , from the annual illicit drug $p<0.001$ ) and more than four times as likely to report using at least one illicit drug from the annual illicit drug index $(\mathrm{OR}=4.32$, $p<0.001$ ). In particular, LB women reported significantly higher rates of using cocaine, downers, hareaticy, tranquilizers, amphetamines, and psychedelics in the past year. Finally, in addition to licit and illicit AOD use, we also examined the prevalence of selected prescription drugs prescribed by a doctor and found that LB women were almost five times as likely to use prescribed antidepressant drugs than heterosexual women $(\mathrm{OR}=4.79, p<0.001)$.

As illustrated in Table IV, multivariate logistic regression confirmed that GB men were less than half as likely to report heavy episodic drinking than were heterosexual men. After adjusting for demographic factors, there were no statistical differences between GB men and heterosexual men in cigarette smoking, alcohol use in the past year, marijuana use before college, marijuana use in the past month, or other illicit drug use. However, GB men were more than twice as likely to have used marijuana in the past year and more than six times as likely have used ecstasy before college. Finally, GB men were almost five times as likely as heterosexual men to use prescribed antidepressants $(\mathrm{OR}=5.33, p<0.001)$.

When considering the AOD use results overall, some similarities between men and women were apparent. For all AOD use measures except for binge drinking in the past 2 weeks and consuming four or more drinks per occasion, odds ratios indicate higher use among LGB students than among heterosexual female and male students. Finally, because response rate and gender distribution differed between the U.S. mail and web survey modes, we ran each of the logistic regression models controlling for mode. Adjusting for survey mode in the logistic regressions did not influence the study results.

\section{Primary and Secondary Consequences of Alcohol and Other Drug Use}

We examined the relationship between sexual identity and each adverse ADDrelated primary and secondary consequence in the past year, by testing separate multivariate logistic regression models for each consequence, and controlling for race, class year, living arrangements, and grade point average (results not shown). Although examination of alcohol use by sexual identity suggested that LB women did not differ from heterosexual women, LB women were significantly more likely to experience 8 of 23 adverse primary AOD consequences. Most notable, LB women were more likely than heterosexual women to have reported driving under the influence of alcohol $(\mathrm{OR}=2.98, p<0.001)$, have unplanned sex after drinking $(\mathrm{OR}=$ 2.98, $p<0.01$ ), have suicidal thoughts after drinking ( $\mathrm{OR}=7.17, p<0.001)$, and sexually harass someone while drinking $(\mathrm{OR}=7.62, p<0.001)$. Reports of primary AOD consequences in the past year differed less for gay/bisexual and heterosexual men. Gay/bisexual men were more likely to report suicidal ideations after drinking $(\mathrm{OR}=3.39, p<0.05)$ and hangovers $(\mathrm{OR}=2.10, p<0.05)$. It is important to note that students who had not consumed alcohol in the past year were not asked about 
primary consequences, as by definition they could not have experienced these events within the past year. Therefore, because heterosexual and LGB students had slightly different rates of past year abstinence, we also examined the prevalence of primary consequences among past year drinkers only. These results mirrored the overall results of the entire sample.

The LGB students were significantly more likely than their heterosexual counterparts to report only 3 of 20 secondary consequences of ADD use in the past year. Specifically, LB women were more likely to have taken care of someone with a drinking or drug problem $(\mathrm{OR}=2.71, p<0.01)$ and to have their sleep disrupted by someone drunk or high $(\mathrm{OR}=1.88, p<0.05)$. GB men were almost three times more likely to have experienced an unwanted sexual advance from someone who was drunk or high $(\mathrm{OR}=2.47, p<0.01)$.

\section{DISCUSSION}

These findings provided partial support for our first hypothesis. We did not find that alcohol use differed significantly between LB women and heterosexual women. However, LB women were at higher risk than heterosexual women for cigarette smoking, marijuana use, ecstasy use, and other illicit drug use among undergraduate women. Additionally, GB sexual identity was significantly associated with marijuana use in the past year and several measures of ecstasy use before college among undergraduate men.

The finding that LB women reported similar drinking behaviors as heterosexual women and GB men reported fewer instances of heavy drinking relative to heterosexual men is similar to other studies using random sampling methods $(2,7,8)$. Among LB and GB students who reported drinking in the past month or past year, LGB drinkers reported more moderate drinking behaviors and less frequent alcohol consumption than did heterosexual students. The finding that GB men had significantly lower rates of heavy episodic drinking than did heterosexual men (29\% vs. $48 \%$ ) is especially significant when considering the negative consequences associated with this drinking behavior $(10,31,36)$.

Findings also provided partial support for the second hypothesis regarding AOD-related consequences. Despite similar drinking behaviors between LB and heterosexual women, LB women reported significantly higher rates of over a third of the primary AOD-related consequences-a finding consistent with other reports in the literature (23-25). In this study, for example, LB women were more likely than heterosexual women to report drunk driving, unplanned sex, and suicidal ideations after drinking. However, there were fewer differences in secondary AOD consequences between LB and heterosexual women. Similarly we found no significant differences between GB and heterosexual men in most (more than 90\%) of primary and secondary AOD-related consequences.

These results have important implications for prevention programs, especially those aimed at college students. For example, the finding that LB women and GB men reported higher rates of illicit drug use supports previous studies that found higher rates of drug use among LGB adolescents and young adults $(4,8)$. Additionally, GB men reported initiating ecstasy use at an earlier age than heterosexual men, while 
LB women reported earlier initiation of marijuana use. This finding is important given previous research indicating that individuals who initiate AOD use at an earlier age are at greater risk for drug-related problems and dependence as young adults (37-39). Further, the fact that LB women were more likely to take care of others with a drug problem suggests a need to target this group for AOD education. Specifically, education about how to recognize and respond to AOD overdose is critical. Given the findings of higher rates of prescribed antidepressant drug use and suicidal ideation among both LB women and GB men, college counselors and administrators must be aware that these students need support services that are sensitive and nonjudgmental.

Several limitations need to be considered when evaluating the study's findings. First, nonresponses could be a potential source of bias because the overall response rate was $52 \%$. Furthermore, there were differences in the demographic characteristics between the obtained sample and the overall student population. Although we controlled for the differences in demographic characteristics in our multivariate models, we acknowledge the departure from the student population as a limitation. Second, because the sample consisted of current full-time students attending an elite research university, it is not representative of the U.S. population attending college and is even less representative of the general U.S. population. Third, because we were unable to assess selection biases with regard to sexual orientation, it was not possible to determine how representative our sample was of the actual LGB population at the institution where the study took place. Finally, although the sample size was sufficient to examine differences between LGB and heterosexual undergraduate students, we were unable to examine differences between lesbian and bisexual women and between gay and bisexual men. Because there were higher proportions of self-identified bisexual women (vs. lesbians) and gay men (vs. bisexuals), these groups may have driven the results for the LB and GB subgroups, given the difference in substance use found within three subgroups among adolescents (8). Future research identifying differences between gay and bisexual men as well as lesbian and bisexual women among college students might be especially helpful for planning prevention and intervention efforts.

Despite a great deal of recent attention given to AOD misuse among college students, there has been inadequate research focusing on LGB student populations $(28,40)$. Research is needed that includes multiple measures of sexual orientation and large random samples of nationally representative undergraduate students in order to generalize results to LGB students nationally (41). Additionally, research is needed that includes large enough samples to permit examination of within-group differences based on race/ethnicity, disability, or other marginalized statuses. Finally, future research is needed that examines the risk and protective factors associated with AOD use/misuse among LGB college students. Because our data were crosssectional, the causal relationships between sexual identity and several health behaviors remain unclear. It has been suggested that self-identified LGB identities fluctuate during the transition from adolescence to young adulthood (42). For instance, we found that female students who self-reported lesbian or bisexual sexual identity tended to be further along in school, suggesting that for female students, sexual identity may not become clear until later in young adulthood. Longitudinal 
research that examines the relationship between the development of sexual identity and AOD use among young adults would be particularly helpful.

\section{ACKNOWLEDGMENTS}

The authors thank Amy Young and the anonymous reviewers for their helpful comments on a previous version of the paper. This study was supported by the University of Michigan, and development of this paper was supported by a National Research Service Award T32 DA 07267 (Sean E. McCabe) from the National Institute on Drug Abuse, National Institutes of Health, and by a research Grant No. K01 AA00266 (Tonda L. Hughes, PI) from the National Institute on Alcohol Abuse and Alcoholism, National Institutes of Health.

\section{REFERENCES}

1. Gruskin EP, Hart S, Gordon N, Ackerson L: Patterns of cigarette smoking and alcohol use among lesbians and bisexual women enrolled in a large health maintenance organization. Am J Public Health 2001; 91:976-979

2. Cochran SD, Keenan C, Schober C, Mays VM: Estimates of alcohol use and clinical treatment needs among homosexually active men and women in the U.S. population. J Consult Clin Psychol 2000; 68:1062-1071

3. Boyd CJ, McCabe SE, d'Arcy H: Ecstasy use among college undergraduates: Gender, race, and sexual identity. Journal of Substance Abuse Treatment, in press.

4. Garofalo R, Wolf RC, Kessel S, Palfrey SJ, DuRant RH: The association between health risk behaviors and sexual orientation among a school-based sample of adolescents. Pediatrics 1998; 101:895-902

5. Cabaj RP: Gays, lesbians, and bisexuals. In: Lowinson JH, Ruiz P, Millman RB, Langrod JG, eds. Substance Abuse: A Comprehensive Textbook. 3rd edn. Baltimore: Williams and Wilkins; 1997:725733

6. Hughes TL, Eliason M: Substance use and abuse in lesbian, gay, bisexual and transgender populations. J Primary Prev 2002; 22:263-298

7. Bloomfield K: A comparison of alcohol consumption between lesbians and heterosexual women in an urban population. Drug Alcohol Depend 1993; 33:257-269

8. Russell ST, Driscoll AK, Truong N: Adolescent same-sex romantic attractions and relationships: Implications for substance use and abuse. Am J Public Health 2002; 92:198-202

9. Johnston LD, O’Malley PM, Bachman JG: Monitoring the Future National Survey Results on Drug Use, 1975-2000, Vol 2 (NIH Publication No. 01-4925). Bethesda, MD: Department of Health and Human Services; 2001

10. Presley CA, Meilman PW, Cashin JR: Alcohol and Drugs on American College Campuses: Use, Consequences, and Perceptions of the Campus Environment, Vol 4: 1992-94. Carbondale: Southern Illinois University, Core Institute; 1996

11. Wechsler H, Lee JE, Kuo M, Lee H: College binge drinking in the 1990's: A continuing problem. Results of the Harvard School of Public Health 1999 College Alcohol Study. J Am Coll Health 2000; 48:199-210

12. DeBord KA, Wood PK, Sher KJ, Good GE: The relevance of sexual orientation to substance abuse and psychological distress among college students. J Coll Stud Dev 1998; 39:157-168

13. Pope HG Jr, Ionescu-Pioggia K, Pope KW: Drug use and life style among college undergraduates: A 30-year longitudinal study. Am J Psychiatry 2001; 158:1519-1521

14. Meilman PW: Alcohol-induced sexual behavior on campus. J Am Coll Health 1993; 42:27-31

15. Wechsler H, Dowdall GW, Maenner G, Gledhill-Hoyt J, Lee H: Changes in binge drinking and related problems among American college students between 1993 and 1997. Results of the Harvard School of Public Health College Alcohol Study. J Am Coll Health 1998; 47:57-68

16. Drug Abuse Warning Network. (2000, Dec.). Club drugs: The DAWN report. Rockville, MD: Office of Applied Studies, Substance Abuse and Mental Health Service Administration

17. Wright SW, Slovis CM: Drinking on campus. Undergraduate intoxication requiring emergency care. Arch Pediatr Adolesc Med 1996; 150:699-702 
18. Abbey A: Acquaintance rape and alcohol consumption on college campuses: How are they linked? J Am Coll Health 1991; 39:165-169

19. Abbey A, Ross LT, McDuffie D, McAuslan P: Alcohol and dating risk factors for sexual assault among college women. Psychol Women Q 1996; 20:147-169

20. Gross WC, Billingham RE: Alcohol consumption and sexual victimization among college women. Psychol Rep 1998; 82:80-82

21. Wechsler H, Moeykens B, Davenport A, Castillo S, Hansen J: The adverse impact of heavy episodic drinkers on other college students. J Stud Alcohol 1995; 56:628-634

22. Wechsler H, Lee JE, Nelson TF, Lee H: Drinking levels, alcohol problems and secondhand effects in substance-free college residences: Results of a national study. J Stud Alcohol 2001; 62:2331

23. Hughes TL, Haas AP, Razzano L, Cassidy R, Matthews A: Comparing lesbians' and heterosexual women's mental health: A multi-site survey. J Gay Lesbian Soc Serv 2000; 11:57-76

24. Hughes TL, Wilsnack SC, Johnson T: Investigating lesbians' mental health and alcohol use: What is an appropriate comparison group? In: Omoto A, Kurtzman H, eds. Recent Research on Sexual Orientation, Mental Health, and Substance Abuse, Washington, DC: APA Books; in press

25. McKirnan DJ, Peterson PL: Alcohol and drug use among homosexual men and women: Epidemiology and population characteristics. Addict Behav 1989; 14:545-553

26. Russell ST, Joyner K: Adolescent sexual orientation and suicide risk: Evidence from a national study. Am J Public Health 2000; 91:1276-1281

27. Abbey, A: Alcohol-related sexual assault: A common problem among college students. J Stud Alcohol 2002; 14(Suppl):118-128

28. Perkins HW: Surveying the damage: A review of research on consequences of alcohol misuse in college populations. J Stud Alcohol 2002; 14(Suppl):91-100

29. McCabe SE, Boyd C, Couper M, Crawford S, d'Arcy, H: Mode effects for collecting alcohol and other drug use data: Web and US mail. J Stud Alcohol 2002; 63:755-761

30. Strote J, Lee JE, Wechsler H: Increasing MDMA use among college students: Results of a national survey. J Adolesc Health 2002; 30:64-72

31. Wechsler H, Lee JE, Kuo M, Seibring M, Nelson TF, Lee H: Trends in college binge drinking during a period of increased prevention efforts. Findings from 4 Harvard School of Public Health College Alcohol Study surveys: 1993-2001. J Am Coll Health 2002; 50:203-217

32. Laumann EO, Gagnon JH, Michael RT, Michaels S: The Social Organization of Sexuality: Sexual Practices in the United States: Chicago: University of Chicago Press; 1994

33. Mays VM, Cochran SD: Mental health correlates of perceived discrimination among lesbian, gay, and bisexual adults in the United States. Am J Public Health 2001; 91:1869-1876

34. McCabe SE: Binge Drinking Among Undergraduate Students: An Examination of Risk Factors Using a Psychosocial Model (Doctoral dissertation, 2000). Dissertation Abstr Intl 2001; 61:2540-A

35. McCabe SE: Gender differences in collegiate risk factors for heavy episodic drinking. J Stud Alcohol 2002; 63:49-56

36. Wechsler H, Davenport A, Dowdall G, Moeykens B, Castillo S: Health and behavioral consequences of binge drinking in college: A national survey of students at 140 campuses. JAMA 1994; 272:16721677

37. Dewit DJ, Adlaf EM, Offord DR, Ogborne AC: Age at first alcohol use: A risk factor for the development of alcohol disorders. Am J Psychiatry 2000; 157:745-750

38. Guo J, Collins LM, Hill KG, Hawkins JD: Developmental pathways to alcohol abuse and dependence in young adulthood. J Stud Alcohol 2000; 61:799-808

39. Zucker RA: The four alcoholisms: A developmental account of the etiologic process. In: Rivers PC, ed. Nebraska Symposium on Motivation: Alcohol and Addictive Behavior. Lincoln: University of Nebraska Press; 1987:27-83

40. Dowdall, GW, Wechsler, H: Studying college alcohol use: Widening the lens, sharpening the focus. J Stud Alcohol 2002; 14(Suppl):14-22

41. Sell RL, Becker JB: Sexual orientation data collection and progress toward Healthy People 2010. Am J Public Health 2001; 91:876-882

42. Gonsiorek JC, Rudolph JR: Homosexual identity: Coming out and other developmental events. In: Gonsiorek JC, Weinrich JD, eds. Homosexuality: Research Implications for Public Policy. Newbury Park, CA: Sage; 1991:161-176 